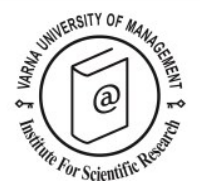

\title{
How do education and training policies determine customer satisfaction and hotels' performance?
}

\author{
Theodoros Stavrinoudis ${ }^{1 *}$ and Moschos Psimoulis ${ }^{2}$
}

Received: 07/09/2016 Accepted: 27/02/2017

\footnotetext{
1 Assistant Professor "Tourism Management", University of the Aegean, Department of Business Administration, 8 Michalon str., 82100 Chios, Greece; tel.: 00306938799541 ; e-mail: tsta@aegean.gr

2 University of the Aegean, Department of Business Administration

* Corresponding author
}

\begin{abstract}
The purpose of this manuscript is to investigate the effect of education and training policies, applicable to hotel employees, on customer satisfaction, HRM performance and perceived financial performance. Based on an extensive literature review, the authors conducted a primary research, using a structured questionnaire which was distributed to the HR managers of hotels. The research proved the positive correlation between education- training policies and customer satisfaction, partially by strengthening the loyalty of HR. The adoption of appropriate educational methods significantly enhances the HRM performance and improves the overall economic performance of hotels. The prerequisite for the successful implementation of education- training policies are the effective training needs analysis and the formulation of appropriate training objectives. The manuscript contributes to the theoretical and empirical knowledge of the importance of education and training policies in the hospitality industry by reaching scientific conclusions and making recommendations to the hotel managers. It can also work as a basis for future research which will focus on connecting business strategies with education- training policies.
\end{abstract}

(c) 2017 Varna University of Management. All rights reserved

Keywords: education and training policies, customer satisfaction, HRM performance, financial performance, employees, hotels, Greece.

Citation: Stavrinoudis, T., M. Psimoulis (2017) How do education and training policies determine customer satisfaction and hotels' performance? European Journal of Tourism Research 17 pp. 177190

\section{Introduction}

In the highly competitive international hospitality industry, the characteristics of the Human Resources (HR) and the Human Resources Management (HRM) practices employed can decisively influence job performance, employees' job satisfaction, customer satisfaction (Stavrinoudis and Floras, 2012; Obedat et al., 2016) and their long-term development (Kyriakidou and Maroudas, 2010). Recent researches have focused on how HRM can affect customer satisfaction (Evanschitzky 
et al., 2011; Feng et al., 2014), hotel company financial performance (Ruzic, 2016) and HRM performance (Ahmad et al., 2010). Employees in the tourism industry are vital for customer satisfaction, mainly through their continuous interaction with the customer. In this context, educational and training programs that improve their behavior, communication and work performance can directly affect customer satisfaction (Saravan and Rao, 2007). Education enhances employees' communication skills and increases their professionalism and dedication (Feng et al., 2014), which means increased revenue for the company through the existence of more loyal customers who consume more (Evanschitzky et al., 2011).

The significance of $H R$ and the respective contribution of education and training to the definition of the characteristics of its quality is widely recognized (Singh et al., 2007). However, over the years, hotels demonstrate a reduced interest for employees with traditional skills training (Baum, 2015), while employers tent to show minimal willingness on spending more money and efforts on their employees' training (Baum, 2007). It has been noted that there is internationally disproportionate emphasis placed on commitment and investment in both employees' training and development and focus on achieving clearly predefined training and quality objectives (Prayag and Hosany, 2015).

This shortage is especially pronounced in Greek hotels and is a primary source of many problems and deficiencies. It is therefore not surprising that the prevalence of a working culture that sidesteps and fails to recognize the need for skilled and trained manpower, regards employment in hotels as temporary and limits the number of employees who want to make a career in the hospitality industry. According to the same logic, amid the crisis many hotels are attempting to reduce their labor costs by hiring new employees with little knowledge and experience, or covering work positions with students (internship). It is understood that the importance of education and training is higher for these employees, as there are many unskilled hotel employees, which leads to the reduction of the value of the touristic service that is being offered (Stavrinoudis et al., 2013).
These findings were the main impetus for the realization of this research, as it is estimated that the contribution of HR education and training can be of particular importance regarding issues of customer satisfaction, improvement of the economic performance of hotels and improvement of the HRM performance.

On the other hand, the majority of worldwide surveys that investigated the relationship between training and HR efficiency (both from a financial perspective and in relation to customer satisfaction) were mainly in construction sector rather than in the services industry and hence in tourism. The lack of uniformity that characterizes the services industry, and includes a large number of different companies, has greatly delayed similar research (Hoque, 1999b). The research conducted in Greece also focused on the construction sector (Katou and Badhwar, 2007) and food production companies (Vlachos, 2008). Tourism enterprises, especially hotels, albeit an important part of the Greek economy, did not participate in similar surveys in the past. The lack of relevant research in Greece also resulted in the conduction of this investigation and has allowed the identification of specific hypotheses regarding the relationship between HR and certain dimensions of hotel performance, HR performance and customer satisfaction.

The main objective of this manuscript is to investigate the effect of HR education and training policies regarding three crucial parameters for the viability and development of hotels, on:

- customer satisfaction

- HRM performance

- perceived financial performance.

In order to fulfill this objective three research hypotheses were formulated, which were checked in a primary research conducted in hotels in Athens and the region of Attica.

\section{Literature review}

The importance of educational and training policies is proven by a number of key parameters or problems related to HR, such as the absence of incentives, lack of dedication to the hotel, the lack of opportunities for 
development, etc. (Meliou and Maroudas, 2011). The degree of employees' satisfaction from on the job training programs actually affects their job satisfaction and organizational commitment (Latif et al., 2013).

\section{HR education-training policies and customer satisfaction}

The main responsibility of the HRM department is to constantly upgrade the quality of HR and also to create an internal environment where employees are encouraged and helped to acquire skills and knowledge, so they can evolve on an individual and corporate level (Armstrong, 2006; Stavrinoudis and Livadioti, 2011). Adapting certain HRM practices (training is one of these practices) contribute in improving the attitudinal and behavioral outputs within the organization (Memon, Salleh and Baharom, 2016).

This can be achieved through the adoption and implementation of specific HR educationtraining policies, which guide employee skills towards well-defined behavior leading to certain performance results. Such a process should seek to exploit the multiple possibilities offered by education within the enterprise in order to strengthen the abilities and efficiency of the staff. This in turn allows the adoption of those behaviors that will enable the effective satisfaction of customer needs, economic viability, business performance, and of course will strengthen the overall HR and HRM performance (Chalofsky, 2008). The research of Feng et al. (2014) demonstrated the direct link between training, employees' performance and their impact on improving the product offered and customer satisfaction. This is because training employees and improving their knowledge and skills can enhance the competitiveness of a hotel and increase employee engagement (Ruzic, 2015) and customer satisfaction.

In contrast to other business sectors, the importance of service in the hospitality industry is significant as the contact between customers and employees is high (Schneider, 2004). The numerous encounters between hotel employees and customers create a mandatory basis for customer evaluations of service quality (Kralj and Solnet, 2010) making the customer satisfaction as one of the key success factors of a hotel. The above mentioned perceptions leaded us to formulate the first hypothesis $(\mathrm{H} 1)$ that "HR educationtraining policies have a positive impact on customer satisfaction".

\section{HR education-training policies and HRM performance}

Education increases competitiveness and productivity of HR (Elmadag et al., 2008) while the proper employee empowerment must be supported by well-structured educational and training policies that helps employees feel that they are part of a team which is constantly trying to improve its performance (Stavrinoudis and Simos, 2016). Besides, companies that provide their employees with equal access to training programs are more likely to have a greater amount of dedicated staff, because they feel that the company is willing to "invest" in them (Dhar, 2014).

As Ramsay et al., 2000 suggested, it is particularly important to implement HRM policies, such as staff training, which are characterized by "great commitment", "high participation" and "high performance". These policies must be implemented extensively in time and in such a way that will serve the development and performance of staff within the hierarchy of the hotels. Martinez-Ros and Orfila-Sintes (2012) argued that the highly skilled executives are more innovative while education and training is a crucial factor towards helping employees achieving individual technical development. By doing so a hotel exploits education and training as a motivational factor (Ruzic, 2015) which also improves employees' performance.

It is necessary for training policies to complement the HRM practices in order to develop the skills of HR and the improvement of the hotel's organizational efficiency (Vlachos, 2008). The educational and training policies adopted by the HRM department should be applied in conjunction with other HR practices of the hotel, so that the training of employees can be consistent with a number of other practices and operations of this department aiming at improving HRM performance (UbedaGarcia et al., 2013). The participation in training 
activities gives employees the opportunity to co-create interactions, introduce new ideas and develop a culture of cooperation, actual engagement and active participation in the hotel's issues (Daniels, 2003; Ramaswamy and Goouillart, 2010). Recent developments suggest that, tourism enterprises must encourage their employees acquiring more and broader skills in order to be more flexible and able to adjust to a greater range of tasks (Baum, 2015).

These ideas underline the importance of analyzing the value of education and training to HRM performance in an industry plagued by high staff turnover (Herrington et al., 2013). From this point, it is imperative to examine the second hypothesis $(\mathrm{H} 2)$ that "HR educationtraining policies have a positive impact on HRM performance".

\section{HR education-training policies and perceived financial performance}

Lack of HR practices and training could create poor organizational culture (Walsh \& Taylor, 2007) creating irreparable damage to hotels' reputation. On the other hand, an interesting survey conducted in the region of Valencia in Spain, by Ubeda-Garcia et al. (2013) confirmed the relationship between HR education and training and the overall performance of hotels. However, other researches indicated that in the majority of hotels (especially small and medium-sized), the employees' education and training is implemented in a fragmented, informal way and without adequate planning (Kotey and Sheridan, 2004) often considered mainly as a cost rather than as a long-term developmental investment. Meanwhile, despite the overall finding that work in the hotels requires personnel with knowledge, employees are not paid accordingly, and this leads to quit their job (Marco-Lajara and Ubeda-Garcia, 2013). This is particularly true of skilled and trained employees who can affect the hotel performance in many ways (Pnevmatikoudi and Stavrinoudis, 2016).

Martinez-Ros and Orfila-Sintes (2012) suggested that during a period of economic crisis improving employees through education and training may help hotels overcome negative consequences and gain competitive advantages. In the highly competitive hospitality market (Peng et al., 2015), it is necessary for hotels' survival to increase their market share, grow their sales (Barrett and O'Connell, 2001; Barba Aragon et al., 2014) and achieve financial returns (Serrat, 2011). Zheng et al. (2006) showed that education has a positive effect on competitiveness, financial results and the commitment of employees, while Munoz and Salinero (2011) argued that companies which conduct educational activities for their HR are significantly more profitable than those who overlook them. In order to confirm the effect of training in perceived financial performance, the third hypothesis $(\mathrm{H} 3)$ have been formed, "HR education-training policies have a positive impact on the perceived financial performance of hotels".

\section{Methodology Variables Analysis}

For this research, independent and dependent variables were used. The education and training policies designed and implemented by the hotels' management constitute the main independent variable. This is divided into three basic parameters: the training objectives, the training evaluation and the training needs analysis. The main variables of the first parameter correspond to various training objectives that meet the education and training policies. The more important training objectives are: enhancing the knowledge and skills of HR, enhancing the attachment and loyalty to the hotel, increasing employee participation, informing about the targets of the company and each department, cultivating and disseminating the organizational culture of the hotel etc.

The second parameter contains variables related to the training evaluation. This includes the existence, or not, of technics aiming at the measurement of the results of the training programs, the evaluation of the degree of knowledge acquisition, the degree of knowledge implementation in the job, the required time to apply the knowledge, training methods assessment etc. The third parameter contains variables related to the detection and analysis of training needs, the existence of technics identifying the training needs of different groups of employees, the degree of employee participation in the configuration of 
the educational objectives of training programs, the employees' assessment of their training needs and the degree to which they were achieved, training needs associated with the business strategy and the goals of the company or individual departments etc.

The dependent variables were "customer satisfaction", "HRM performance" and "perceived financial performance". The first variable investigated the extent to which education and training of HR has improved customer satisfaction levels. More specifically, it examined whether the levels of customer loyalty increased, or not, due to the implementation of HR education and training policies, leading to the existence of more repeaters. Also, to what extent the training of HR has improved the quality of services offered, leading to the reduction in complaints.

The second variable investigated the degree to which the education and training policies have a direct impact on a) the targets set by the company for HRM, both operationally and strategically and b) the qualitative improvement of HR. This includes variables associated with increasing the motivation of employees, enhancing the level of their empowerment, improving employees' ability to respond to future changes in their working environment, reducing absenteeism etc. The third variable investigated the influence of educational and training policies in perceived financial performance. This includes variables related to increased productivity, reduction of ineffective periods- especially during winter time, improvement of the competitive position of the hotel and enhancement of economic results. All the independent and dependent variables were measured with the use of 10 point Likert scale from 1 to 10 . Table 1 presents the independent and dependent variables.

\section{Research participants and sample design}

The survey was conducted in the region of Attica, which covers $3 \%$ of the total geographical area of the country but includes $35.39 \%$ of the total resident population. The region of Attica encompasses the entire metropolitan area of Athens, the capital of Greece. It is one of the major tourist destinations in Greece, which in 2014 had $3,388,322$ tourist arrivals and ranked in the 3rd position of all regions in terms of arrivals. As far as tourism supply is concerned, a great number of luxury (both local and international) hotels are situated in Attica.

Questionnaires were distributed to five, four and three-star hotels. The sample resulted from the Hellenic Chamber of Hotels and the valid Tourist Guide "Greek Travel Pages", which is one of the longest-serving and most reliable sources of information for the Greek tourism sector. Based on the data from these two sources, there were 175 five, four and threestar hotels in Attica region. The hotels that were excluded were the following:

a) Hotels that belonged to a chain and followed education and training policies which were the same for all members. In that case, only one questionnaire was completed per group.

b) Two and one star hotels, rooms to let etc., because either they were small family units (which had no organized HR department), or the owners-managers were unable to complete the questionnaire.

c) Hotels that have ceased to operate.

d) Hotels which are situated in the small islands of Attica and have been closed during the period of primary research (January- February, 2015)

Thus, the total sample of our research amounted to 117 hotels. The questionnaires were distributed and collected by the

Table 1. Independent and dependent variables of the research

\begin{tabular}{lll}
\hline Independent Variables & & Dependent Variables \\
\hline Education \& Training Policies & Training Objectives & Customer Satisfaction \\
& Training Evaluation & HRM Performance \\
& Training Needs Analysis & Perceived Financial Performance \\
\hline
\end{tabular}


researchers, to the HR managers, or (in hotels that lacked an HR manager) the executive who was responsible for HR (usually general manager or owner). In order for the completion of the questionnaire to become easier and faster, a relevant link- from where the participants could have access to the questionnaire using a specific code- was sent by e-mail.

To ensure the highest possible participation in the survey, researchers contacted a number of hotels more than once (either by e-mail or phone) in order thereby to secure their response. Each case of delayed response was handled by researchers, who sometimes had to wait several days before the completion of the questionnaire. The incitement effort to complete the questionnaire stopped when there was a clear refusal to participate in the research on the part of the respondent. The number of completed questionnaires was 104 ( $88.9 \%$ completion rate), which is a satisfactory amount and ensures that the analysis of the variables can be effective and reach firm conclusions (Agresti, 2002).

\section{Survey instrument}

The survey was conducted using a structured questionnaire (Javeau, 2000), which the researchers partially based on the research of Ubeda-Garcia et al. (2013), who examined the variables of training policy which have a positive impact on organizational performance on the eastern coast of the Iberian Peninsula, and more specifically in the region of Valencia. Before the main research, there was a smallscale pilot research (with the participation of five respondents who met the characteristics of the sample) and worked as HR managers or general managers in hotels outside the Attica region. Thus, the data which had to comprise the questionnaire were finalized and effectively adapted to the Greek hospitality industry. To avoid influencing respondents, special care was taken for the questions to be balanced. The pilot research ensured that the questions were clear and understandable for the participants and the filling process was easy, so as to: a) avoid the resignation of participants completing the questionnaire and b) increase the response rate. Questions alternated between different pages and their wording varied accordingly, thereby avoiding creating a predictable research pattern that would cause the participants to respond in the same way and based on previous data. Finally, questions were verified with the help of two consultants who came from the area of HRM and vocational education and training in tourism, thus ensuring that any personal bias would not affect the research.

The final questionnaire consisted of three sections, containing twenty-nine questions, most of which were closed type Likert scale questions (Stathakopoulos, 2001). The first section contained questions about the hotel (e.g. number of rooms, employees, class etc.). The second explored the hotel strategy adapted (e.g. cost strategy, differentiation strategy). The third section examined the training strategy applied by the hotel, and especially the education- training policies and the extent to which these have affected the customer satisfaction, the HRM performance and the perceived financial performance.

\section{Analysis of data}

The analysis of data was performed using the statistical software package SPSS Version 20. "Multiple Regression" analysis (Enter method) was used because it enables statistical forecasting of a dependent variable- criterion by one or more independent variables. It calculates the ratio of multiple relevance i.e. the degree of correlation between the dependent variable and the independent variables (Pavlopoulos, 2006).

\section{Research findings \\ Effect of education-training policies on customer satisfaction}

The first to be investigated was the first hypothesis $(\mathrm{H} 1)$ which claims that education and training policies have a positive impact on customer satisfaction. The development of a positive internal business culture, through education-training, and the dedication of employees to this culture can clearly lead to improved customer service and consequently higher customer satisfaction. These are key conditions for success for the hotels. The analysis shows (see table 2) that the slope of the regression line is significantly different from zero, $F=38.501, p<0.001$. 
Table 2. Results for education- training policies and customer satisfaction

\begin{tabular}{lcc}
\hline Independent Variables & \multicolumn{1}{c}{$\begin{array}{c}\text { Dependent Variable } \\
\text { Customer Satisfaction }\end{array}$} \\
\hline Training Objectives & standardized $\beta$ and significance & $\mathrm{t}$ \\
Training Evaluation & $0.615^{*}$ & 4.986 \\
Training Needs Analysis & -0.014 & -0.121 \\
\hline Model Statistics & $0.218^{* *}$ & 1.823 \\
$\mathrm{R}$ & & \\
$\mathrm{R}^{2}$ & 0.783 & \\
F- statistics & 0.613 \\
p-value & 38.501 \\
\hline Model & $<0.001$ & \\
Regression & $\mathbf{d f}$ \\
Residual & 3 & \\
Total & 73 & \\
\hline
\end{tabular}

Note: Significant at: ${ }^{*} p<0.001{ }^{* *} p<0.10$

Table 3. Results for education- training policies and HRM performance

\begin{tabular}{lcc}
\hline Independent Variables & $\begin{array}{c}\text { Dependent Variable } \\
\text { HRM Performance }\end{array}$ \\
\hline Training Objectives & standardized $\beta$ and significance & $\mathrm{t}$ \\
Training Evaluation & $0.592^{*}$ & 5.526 \\
Training Needs Analysis & 0.133 & 1.324 \\
\hline Model Statistics & $0.176^{* *}$ & 1.688 \\
$\mathrm{R}$ & & \\
$\mathrm{R}^{2}$ & 0.841 & \\
F- statistics & 0.708 & \\
p-value & 58.872 & \\
\hline Model & $<0.001$ & \\
Regression & df \\
Residual & 3 & \\
Total & 73 & \\
\hline
\end{tabular}

Note: Significant at: ${ }^{*} p<0.001^{\star *} p<0.10$

An overview of regression coefficients shows that two of the three independent variables contribute significantly to predicting the dependent variable. These variables are the training objectives $(b=0.615, t=4.986, p<0.001)$ and training needs analysis $(b=0.218, t=1.823$, $\mathrm{p}<0.001)$.

The analysis of the above data shows that the first hypothesis (H1) "The education- training policies have a positive impact on customer satisfaction" is confirmed by the findings of this survey. $R^{2}$ is equal to 0.613 and $p<=0.01$, so the variables of education- training policies have a significant positive influence on customer satisfaction. This result serves to confirm previous research (Malhotra et al.,
2007; Muller et al., 2013; Kaynak, 2013) which claims that trust and loyalty, as well as good corporate reputation is earned through employee loyalty which the proper implementation of education leads.

In the hospitality industry, HR can play a key role in customer satisfaction and quality servicing. The intangible nature of their work integrates the overall visitor experience through provider-client interaction, forming the overall image and the brand of the hotel. Employees and the qualitative dimensions of their work are key determinants in both customer satisfaction and the quality servicing (Saravan and Rao, 2007). 


\section{Effect of education and training policies on HRM performance}

The second hypothesis $(\mathrm{H} 2)$ was tested; more specifically, it was investigated whether education and training policies have a positive impact on the overall HRM performance. For the examination of the extent of the impact, it was examined how the dependent variable of HRM performance is connected with three independent variables (training objective, training evaluation and training needs analysis) which are related to education-training policies.

The analysis shows that the slope of the regression line is significantly different from zero, $(F=58.872, p<0.001)$. As it can be seen in table 3 , the multiple correlation coefficients "R" is equal to 0.841 , while the adjusted coefficient of determination $R^{2}$ is equal to 0.708 . These results indicate that the influence of the independent variables can explain $71 \%$ of the variance of the number of HRM performance. Therefore, it was concluded that the second research hypothesis "education- training policies have a positive impact on HRM performance" is valid.

Of the three independent variables, and based on the overview of regression coefficients, one (training objectives) contributes significantly to predicting the dependent variable $(b=0.592$, $t=5.526, p<0.001)$. Therefore, we conclude that HRM performance is higher, when the training objectives are in a big scale and widely distinct.
These results are consistent with the earlier survey findings of Katou and Budhwar (2007), who argued that HR education- training policy, HRM performance and the overall business performance are closely related. Given the impact of the objectives of education and training on HRM performance, the adoption of educational programs that emphasize the adaption of HR to future changes in the wider environment of hotels is required, as is developing HR that will acquire faceted and adaptive skills. The successful implementation of educational programs contributes positively to business performance and the overall HRM performance. Therefore, the business strategy and long-term planning of hotels must be directly related to HR education and training, so they can have positive results.

\section{Effect of education - training policies on perceived financial performance}

The third research hypothesis $(\mathrm{H} 3)$ examines whether the education and training policies have a positive impact on the perceived financial performance. The examination of the results (see table 4) shows that the correlation coefficient $R$ is equal to 0.829 , while the coefficient of determination $R^{2}$ is equal to 0.688 . The preceding table shows that the slope of the regression line is significantly different from zero $(F=53.605, p<0.001)$. The data analysis shows that the third hypothesis "The HR education- training policies have a positive impact on the perceived financial

Table 4. Results for education- training policies and perceived financial performance

\begin{tabular}{lcc}
\hline Independent Variables & \multicolumn{2}{c}{$\begin{array}{c}\text { Dependent Variable } \\
\text { Perceived Financial Performance }\end{array}$} \\
\hline Training Objectives & standardized $\beta$ and significance & $\mathrm{t}$ \\
Training Evaluation & $0.645^{*}$ & 5.821 \\
Training Needs Analysis & 0.037 & 0.352 \\
Model Statistics & $0.193^{* *}$ & 1.794 \\
$\mathrm{R}$ & & \\
$\mathrm{R}^{2}$ & 0.829 & \\
F- statistics & 0.688 \\
p-value & 53.605 \\
\hline Model & $<0.001$ & \\
Regression & $\mathbf{d f}$ & \\
Residual & 3 & \\
Total & 73 & \\
\hline
\end{tabular}

Note: Significant at: ${ }^{*} p<0.001{ }^{* *} p<0.10$ 
performance of hotels" has a positive $R^{2}=0.69$, $p<=0.01$ and is confirmed.

As in the case of $\mathrm{H} 1$, two of the three independent variables contribute significantly to predicting the dependent variable. These are the training objectives $(b=0.645, \quad t=5.821$, $p<0.001)$ and training needs analysis $(b=0.193$, $\mathrm{t}=1.794, \mathrm{p}<0.001)$.

Two previous studies have suggested that education and training are directly linked to the organizational performance of an enterprise, which affects economic performance (Paul and Anantharaman, 2003; Guerrero and BarraudDidier, 2004). However, in recent years the mediator tests are rare, so it cannot be verified if the organizational performance essentially mediates the relationship between educationtraining and financial results (Tharenou et al., 2007). This research confirms that investment in the education and training of employees has a long-term positive effect on the economic results of hotels. Furthermore, based on the first hypothesis of the research, increased customer satisfaction can enhance the perceived financial performance. Hotels are required to focus on the HR training as a means of improving the quality of their services and thus their economic performance (Yoo and Park, 2007).

\section{Conclusions and industry implications}

This research constitutes a focused investigation of the effects of HR education and training policies in the hotels' performance and their customer satisfaction. It contributes to the enrichment of the existing body of knowledge through an original research in a scientific field that has not been sufficiently explored in the hospitality sector, expanding the scientific debate on the importance of HR educationtraining for the sustainability, the development of hotels and the improvement of their performance.

A statistical analysis of the research findings allows us to formulate specific scientific conclusions- theoretical implications on the one hand and recommendations- suggestions to hotels' managers and executives on the other. On a theoretical level, it is confirmed that there is a direct and positive relationship between education- training policies and customer satisfaction. The research concluded that the application of appropriate education- training policies allows for the cultivation of an upgraded business culture that focuses on the quality of the product offered, leading to increased customer satisfaction. This is achieved mainly through the enrichment of the qualitative characteristics of $\mathrm{HR}$ and the consequent improvement of the experience offered, but only on the condition that there are appropriate training objectives that respond to the characteristics and needs of each group of employees. It is crucial for the implementation of the training activities to be preceded by a detailed training needs analysis.

The adoption of appropriate education and training policies is related to enhancing the loyalty of HR to the hotel. Through education and training, employees feel part of the production process, part of the hotel and experience higher security, realizing that the hotel invests in them and their work. Strong bonds are formed between employees and the company, increasing their loyalty, which has a direct impact both on improving the quality of the services offered and also on customer satisfaction and the level of their confidence in the hotel. The results of our survey are consistent with the view that education contributes to strengthening the commitment of employees, which can lead to improved quality of customer service and thus to customer satisfaction (Evanschitzky et al., 2011).

What became clear is that education and training largely allows and helps facilitate the adaptation of staff to future changes made either in the internal or the external environment of the hotel. The existence of welldesigned education and training policies improves the skills of HR and often allows them to develop new ones that they did not have before. The results of this survey confirm the view of Lopez-Cabrales et al. (2006) and Preissl (2000) that hotels must meet modern challenges (technological, etc.), where knowledge acquired by employees through education and training policies should be such as to enable them to contribute to the development of business and secure its position in the contemporary tourist market. 
However, it is necessary that these policies are designed and implemented efficiently with particular emphasis on proper analysis of training needs and a clear formulation of training objectives to be achieved. This becomes more difficult in the hospitality industry, where due to the complex nature of the product, there are employees with different characteristics and different skills and therefore the adoption of numerous educational programs based on different training needs and training objectives is required.

On a secondary level, the applied education and training policies are directly related to the HRM performance and thereby the overall business performance. The connection of education and training activities with the HR performance of hotels increases according to how clearly defined the training objectives are and how efficiently they are served. The survey results are consistent with the view of Mullins (2007) that each hotel company should support continuing education and training of $\mathrm{HR}$, as it is an important long-term investment. This indicates the positive correlation between education and training policies and performance of enterprises belonging to the hospitality industry, because the more wellorganized and adequate the HR training is, the more enhanced the overall performance of the hotel and of HRM is. This finding shows that education develops unique competitive advantages that increase hotel effectiveness and of course profitability. This conclusion confirms the view of Guthrie et al. (2002) that the various $H R$ skills can be turned into a competitive advantage, allowing the hotel to differentiate itself from its competitors.

In terms of economic performance, it became clear that the implementation of appropriate education and training policies can improve the overall economic performance of hotels over time, increasing revenue and probably profitability. Therefore, it can be supported the positive connection between the offer of organized (after training need analysis) and properly designed (based on predefined training objectives) education- training and achieving positive financial performance for hotels. However, over the last six years of the economic recession, the reality in Greek hotels has shown that too often training has been addressed unilaterally as a cost. Moreover, not only are training costs reduced but also HR motives for increasing their performance are limited due to significant pay cuts. A key finding of this research is that HR training can burden the finances of the company at first, but in the long term it mainly increases cash flow and earnings thus becoming an important investment for the company itself.

Training is an important operation of HRM and in no case should HR managers apply it spasmodically and as a separate operation not related to the others. It requires proper analysis of training needs, effective definition of training objectives, rational planning of the program, proper organization and methodical implementation in a way that serves the long-term strategy of the hotel and the training needs arising from the goals which have been set in short, and longer term. Because of its complexity, HR training requires time, effort and money and for good results is essential for executives who implement it to examine numerous parameters, but mainly the will and desire of employees for improvement and development within the company, so that is can, among other things, serve as a motivational factor. Hotel managers should not treat the educational programs as an end in itself, but must adapt to training objectives, which will be updated regularly and will meet the needs and shortcomings related to HR. Of course, the educational processes should be applied in a methodical and definite way in any case.

Corporate education-training policy should be tailored to the needs of each department of the hotel and serves individual and business targets. The design of the education and training should measure and seriously control the description and the basic subject of each job separately, and the department to which it belongs. There should not be the same training content for all employees, nor should it be transmitted in the same way. It should be understood that training methods must be tailored to the needs of each job (if possible), each department with the primary aim of improving the trainee, that he in turn will give productive results that will affect the hotel's 
product and the degree of customer satisfaction. In parallel, education and training policies should be subject to continuous monitoring and reassessment in order to be improved both in terms of methodology and their content, in order for the knowledge and skills gained by the employees to be implemented and used in their work performance in the future. Otherwise there is a risk that employees and the hotel will not perform as intended, and the educational effort will not be successful. HR managers should always take into account the fact that for the selection of an appropriate training program, it should be estimated all the possible results from its implementation, but also the extent to which employees are willing and able to respond to it.

\section{Limitations and Further research}

The main limitation of this research has to do with the difficulties involved in carrying out research with employees, i.e. workload; employees are often quite reserved etc. Another limitation is the geographical area of the research (Attica- Athens) which means that the results of this survey do not necessarily apply to hotels in other destinations, for example classic seasonal ones. Therefore, generalizing the results and suggestions of this research and implementing them in the overall hospitality industry of the country is not a safe approach.

Future research on the subject could focus on the study of education and training policies and their effect on customer satisfaction, HRM performance and perceived financial performance of hotels in more-different geographic locations. This offers the opportunity to export potential adequate and safer results and the possibility for comparisons and reaching conclusions among hotels with different characteristics (e.g. urban hotels, resorts) or hotels engaging in different markets. The researchers of this manuscript estimate that possible future research would be interesting to focus on connecting business strategies with specific education-training policies aiming to link the choice of an education-training policy with specific strategic business objectives to be served by this choice.

\section{References}

Agresti, A. (2002) Categorial data analysis. $2^{\text {nd }}$ edition. New Jersey: John Wiley and Sons Inc.

Ahmad, R., Solnet, D. and Scott, N. (2010) Human resource practices system differentiation: a hotel industry study. Journal of Hospitality and Tourism Management 17, 72-82.

Aragon, M.I.B., Jimenez, D.J. and Valle, R.S. (2014) Training and performance: The mediating role of organizational learning. Business Research Quarterly 17, 161-173.

Armstrong, M. (2006) Strategic Human Resource Management: A guide to action. $3^{\text {rd }}$ edition. London and Philadelphia: Kogan Page.

Barrett, A., O'Connell, P.J. (2001) Does training generally work? The returns to in-company training. Industrial and Labor Relations Review 54 (3), 647-662.

Baum, T. (2007) Human resources in tourism: still waiting for change. Tourism Management 28, 1383-1389.

Baum, T. (2015) Human resources in tourism: Still waiting for change? - A 2015 reprise. Tourism Management 50, 204-212.

Chalofsky, N. (2008) Work-life programs and organizational culture: the essence of workplace community. Organizational Development Journal 26 (1), 11-18.

Daniels, S. (2003) Employee training: a strategic approach to better return on investment. Journal of Business Strategy 24 (5), 39-42.

Dhar, L.R. (2014) Service quality and the training employees: The mediating role of organizational commitment. Tourism Management 46, 419-430.

Elmadag, A.B., Ellinger, A.E. and Franke, G.R. (2008) Antecedents and consequences of frontline service employee commitment to service quality. Journal of Marketing Theory and Practice 16 (2), 95-110.

Evanschitzky, H., Groening, C., Mittal, V. and Wunderlich, M. (2011) How employer and employee satisfaction affect customer satisfaction: An spplication to franchise services. Journal of Service Research 14 (2), 136-148.

Feng, T., Wang, D. and Prajogo, D. (2014) Incorporating human resource management initiatives into customer services: Empirical 
evidence from Chinese manufacturing firms. Industrial Marketing Management 43, 126135.

Guerrero, S. and Barraud-Didier V. (2004) High-involvement practices and performance of French firms. International Journal of Human Resource Management 15 (8), 1410-1425.

Guthrie, J.P., Spell, C.S. and Nyamori, R.O. (2002) Correlates and consequences of high involvement work practices: the role of competitive strategy. International Journal of Human Resource Management 13 (1), 183197.

Herington, C., McPhail, R. and Guilding, C. (2013) The evolving nature of hotel HR performance measurement systems and challenges arising: An exploratory study. Journal of Hospitality and Tourism Management 20, 68-75.

Hoque, K. (1999) Human resource management and performance in the UK hotel industry. British Journal of Industrial Relations 37 (3), 419-443.

Javeau, C. (2000) L'enquête par questionnaire: Manuel à l'usage du praticien. Athens: Typothito (in Greek).

Katou, A.A. and Budhwar, P.S. (2007) The effect of human resource management policies on organizational performance in Greek manufacturing firms. Thunderbird International Business Review 49, 1-35.

Kaynak, H. (2013) Total Quality Management and Just-In-Time purchasing: their effects on performance of firms operating in the U.S. Rutledge Publisher.

Kotey, B. and Sheridan, A. (2004) Changing HRM practices with firm growth. Journal of Small Business and Enterprise Development 11, 474-485.

Kralj, A. and Solnet D. (2010) Service climate and customer satisfaction in a casino hotel: An exploratory case study. International Journal of Hospitality Management 29, 711719.

Kyriakidou, O. and Maroudas, L. (2010) Training and development in British hospitality, tourism and leisure SMEs. Managing Leisure 15, 32-47.

Latif, K.F., Jan, S. and Shaheen, N. (2013) Association of training satisfaction with employee development aspect of job satisfaction. Journal of Managerial Sciences 7 (1), 159-178.

Lopez-Cabrales, A., Valle, R. and Herrero, I. (2006) The contribution of core employees to organizational capabilities and efficiency. Human Resource Management 45 (19), 81109.

Malhotra, N., Budhwar, P. and Prowse, P. (2007) Linking rewards to commitment: An empirical investigation of four UK call centers. International Journal of Human Resource Management 18 (12), 2087-2095.

Marco-Lajara, B. and Ubeda-Garcia, M. (2013) Human resource management approaches in Spanish hotels: an introductory analysis. International Journal of Hospitality Management 35, 339-347.

Maroudas, L., Silignaki, D., Stavrinoudis, Th. and Theofanidis, P. (2013) Factors influencing education, training and development in the Greek hospitality industry. A case study. Paper presented at the 5th International Scientific Conference Tourism Trends and Advances in the 21st Century. Rhodes.

Martinez-Ros, E. and Orfila-Sintes, F. (2012) Training plans, manager's characteristics and innovation in the accommodation industry. International Journal of Hospitality Management 31, 686-694.

McNeese-Smith, D. K. (2001) A nursing shortage: building organizational commitment among nurses. Journal of Healthcare Management 46 (3), 173-187.

Meliou, E. and Maroudas, L. (2011) Career development in the hospitality industry in Greece: implications for human resource practices. Journal of Human Resources in Hospitality and Tourism 10 (2), 218-233.

Memon, M.A., Salleh, R. and Baharom, M.N.R. (2016) The link between training satisfaction, work engagement and turnover intention. European Journal of Training and Development, 40 (6), 407-429.

Muller, M., Geyer, W., Soule, T., Daniels, S. and Cheng, L. T. (2013) Crowdfunding inside the enterprise: employee-initiatives for innovation and collaboration. Paper presented at the SIGCHI Conference on Human Factors in Computing Systems, Paris. 
Mullins, L. (2007) Management and organizational behavior. 8th edition. Prentice Hall.

Munoz-Castellanos, R.M. and Salinero-Martin M.Y. (2011) Training as a source of competitive advantage: Performance impact and the role of firm strategy, the Spanish case. The International Journal of Human Resource Management 22 (3), 574-594.

Obedat, S.M., Rebecca, M. and Bray, M. (2016) The link between high performance work practices and organizational performance: empirically validating the conceptualization of HPWP according to the AMO model. Employee Relations: The International Journal 38 (4), 1-24.

Paul A.K. and Anantharaman R.N. (2003) Impact of people management practices on organizational performance: analysis of causal model. International Journal of Human Resource Management 14 (7), 1246-1266.

Pavlopoulos, V.G. (2006) Introduction to statistical data processing with SPSS for windows. Athens: National and Kapodistrian University of Athens.

Peng, J., Zhao, X. and Mattila, A. (2015) Improving service management in budget hotels. International Journal of Hospitality Management 49, 139-148.

Pnevmatikoudi, K. and Stavrinoudis, Th. (2016) Classification of hotel performance measurement indicators presented in the international scientific research. European Journal of Tourism Research 12, 82-98.

Prayag, G. and Hosany, S. (2015) Human resource development in the hotel industry of Mauritius: myth or reality? Current Issues in Tourism 18 (3), 249-266.

Preissl, B. (2000) Service innovation: what makes it different? Empirical evidence from Germany in innovations systems. In Metcalfe, J.S. and Miles, I. (eds.) The Service Economy. Boston: Kluwer Academic Publishers.

Ramaswamy, V. and Goouillart, F. (2010) The power of co-creation: build It with them to boost growth, productivity, and profits. New York: Free Press.

Ramsay, H., Scholarios, D. and Harley, B. (2000) Employees and high performance work systems: Testing inside the black box.
British Journal of Labour Relations 38, 501531.

Ruzic, M.D. (2015) Direct and indirect contribution of HRM practice to hotel company performance. International Journal of Hospitality Management 49, 56-65

Salas, E. and Cannon-Bowers, J.A. (2001) The science of training: a decade of progress. Annual Review Psychology 52, 471-499.

Saravan, R. and Rao, K.P. (2007) Measurement of service quality from the customer's perspective - an empirical study. Total Quality Management and Business Excellence 18 (4), 435-449.

Schneider, B. (2004) Welcome to the world of services management. Academy of Management Journal 18 (2), 144-150.

Serrat, J.M.B. (2011). Quality of hotel service and consumer protection: a European contract law approach. Tourism Management 32 (2), 277-287.

Singh, N., Hu, C. and Roehl, W.S. (2007) Text mining a decade of progress inhospitality human resource management research: identifying emerging thematic development. International Journal of Hospitality Management 26 (1), 131-147.

Stathakopoulos, V. (2001) Market research methods. Athens: Stamoulis.

Stavrinoudis, Th. and Floras, M. (2012) Enhancing performance through innovative HRM practices and the role of business strategy. Evidence from Greek city hotels. Paper presented at the $2^{\text {nd }}$ International Scientific Conference Advances in Hospitality and Tourism Marketing and Management. 24-27 May, Corfu.

Stavrinoudis, Th. and Livadioti, G. (2011) Researching the implementation of motivation practices in human resources in hotels. An experience from a Greek resort. International Journal of Leisure and Tourism Marketing 2 (1), 4-23.

Stavrinoudis, Th. and Simos, D. (2016) Factors affecting hotel employees' perception and attitude towards empowerment. Journal of Human Resources in Hospitality and Tourism 15 (4), 416-439.

Tharenou, P., Saks, A.M. and Moore, C. (2007) $A$ review and critique of research on training and organizational-level outcomes. Human Resource Management Review 17, 251273. 
Ubeda-Garcia, M., Marco-Lajara, B., SabaterSempre, V. and Garcia-Lillo, F. (2013) Does training influence organizational performance? Analysis of the Spanish hotel sector. European Journal of Training and Development 37 (4), 380-413.

Vlachos, I. (2008) The effect of human resource practices on organizational performance: Evidence from Greece. International Journal of Human Resource Management 19, 74-97.

Walsh, K. and Taylor, M.S. (2007) Developing in-house careers and retaining management talent: what hospitality professionals want from their jobs. Cornell Hotel and Restaurant Administration Quarterly 48 (2), 163-182.

Yoo, D.K. and Park, J.A. (2007) Perceived service quality: Analyzing relationships among employees, customers and financial performance. International Journal of Quality and Reliability Management 24 (9), 908-926.

Zheng, C., Morrison, M. and O'Neill, G. (2006) An empirical study of high performance HRM practices in Chinese SMEs. International Journal of Human Resource Management 17 (10), 1772-1803. 